\title{
The role of Hi Fidelity simulation in designing emergency airway management algorithms: The experience of the UK National Tracheostomy Safety Project
}

DOI:

10.1136/bmjstel-2017-000267

\section{Document Version \\ Accepted author manuscript}

Link to publication record in Manchester Research Explorer

Citation for published version (APA):

McGrath, B., Doherty, C., Moore, J., Bates, L., Hughes, G., Atkinson, D., \& Donaldson, H. (2018). The role of Hi Fidelity simulation in designing emergency airway management algorithms: The experience of the UK National Tracheostomy Safety Project. BMJ Simulation \& Technology Enhanced Learning. https://doi.org/10.1136/bmjstel2017-000267

\section{Published in:}

BMJ Simulation \& Technology Enhanced Learning

\section{Citing this paper}

Please note that where the full-text provided on Manchester Research Explorer is the Author Accepted Manuscript or Proof version this may differ from the final Published version. If citing, it is advised that you check and use the publisher's definitive version.

\section{General rights}

Copyright and moral rights for the publications made accessible in the Research Explorer are retained by the authors and/or other copyright owners and it is a condition of accessing publications that users recognise and abide by the legal requirements associated with these rights.

\section{Takedown policy}

If you believe that this document breaches copyright please refer to the University of Manchester's Takedown Procedures [http://man.ac.uk/04Y6Bo] or contact uml.scholarlycommunications@manchester.ac.uk providing relevant details, so we can investigate your claim.

\section{OPEN ACCESS}


The role of Hi Fidelity simulation in designing emergency airway management algorithms: The experience of the UK National Tracheostomy Safety Project

Brendan A McGrath, ${ }^{1,2,3}$ Catherine Doherty, ${ }^{9}$ John A Moore, ${ }^{5}$ Lucy Bates, ${ }^{4}$ Hannah Donaldson 6 , Gareth Hughes, 3,7,8 Dougal Atkinson, ${ }^{5}$

1. Consultant in Anaesthesia and Intensive Care Medicine, University Hospital South Manchester NHS Foundation Trust, Manchester, UK.

2. Honorary Senior Lecturer, University of Manchester

3. Manchester Academic Health Sciences Centre

4. Consultant in Anaesthesia and Intensive Care Medicine, Royal Bolton Hospital, UK.

5. Consultant in Anaesthesia and Intensive Care Medicine, Central Manchester NHS Foundation Trust, Manchester, UK.

6. Clinical Fellow in Intensive Care Medicine, University Hospital South Manchester NHS Foundation Trust, Manchester, UK.

7. Specialty Trainee in Intensive Care and Respiratory Medicine, University Hospital South Manchester NHS Foundation Trust, Manchester, UK.

8. Honorary Lecturer, University of Manchester

9. Consultant in Paediatric Anaesthesia, Central Manchester NHS Foundation Trust, Manchester, UK. 
Correspondence to: Dr H. Donaldson, Acute Intensive Care Unit, University Hospital South Manchester, Southmoor Road, Wythenshawe, Manchester, UK. M23 9LT.

Email: hdonaldson@doctors.org.uk

Tel: $\quad 01612916420$

Fax: 01612916421

\section{Key words:}

Tracheostomy

Laryngectomy

Airway Emergency

Simulation

Intensive care

Word count: 997 


\section{Introduction}

A variety of simulation-based strategies have been developed to facilitate technical and non-technical learning in simulated airway scenarios, some of which follow predetermined algorithms to guide the responders. $[1,2]$ However, simulation can also be used to devise the responses to emergency scenarios; particularly useful for relatively rare events. We describe this novel use of in-situ simulation to iteratively test and refine practice guidelines during simulated tracheostomy emergencies. These methods can challenge established expert peer review processes for developing airway algorithms.

\section{Methods}

The UK National Tracheostomy Safety Project (NTSP) was tasked with improving emergency tracheostomy management. We recognised that feedback from simulated scenarios could be used in development of emergency algorithms (Figure 1). A Working Party was established comprising medical, nursing and allied health professionals with experience of simulation training and tracheostomy care, supported by representatives of key organisations with a stated interest in airway management.[2]

Four distinct simulated scenarios were developed from clinical reports.[3] Manikins deteriorated physiologically (progressive hypoxia for example), intended to prompt specific actions from participants. Scenarios were tested for validity by four members of the Working Party (BM, DA, LB, JM) prior to consenting multidisciplinary participants attempting them. Formal ethical approval was not required but local research 
governance procedures were followed. Simulators used were SimMan ${ }^{\mathrm{TM}}$ Essential (Laerdal Ltd, Norway) and MetiMan ${ }^{\mathrm{TM}}$ (CAE Healthcare, Canada).

A typical development session comprised the following steps:

1. A briefing, familiarising the participants with both the simulator and the draft algorithm. Candidates were asked to rigidly follow the algorithm steps.

2. The standard scenario was commenced and the draft algorithm followed. Observers used the following criteria to assess performance (of the algorithm):

a. Prolonged desaturation ( $\mathrm{SpO} 2<90 \%$ for $>5 \mathrm{mins})$

b. Significant inaction (e.g. pause of $>1$ min, asking for help, continuing with the same algorithm step when faced with on-going deterioration)

c. Achievement of the scenario's key learning objectives

d. Successful management of the scenario (objective assessment combined with improvement in simulated physiological state)

e. Overall time taken to complete the scenario (defined as return to SpO2 $>90 \%$ and achieving the learning outcome, candidate unable to continue or cardiac arrest occurring in the scenario)

3. A debrief, consisting of candidate feedback plus a discussion of how easy the algorithm was to follow and reasons for any deviation from the current draft. 
4. The steps of the draft algorithm were altered if observers agreed that the scenario had been managed unsuccessfully.

5. A different standard scenario was immediately undertaken. If the adjusted algorithm resulted in improved performance, the amendment was retained for future evaluations.

6. Where two independent candidates' performance resulted in the same recommendation, the algorithm was amended and the latest version used for future evaluations.

Algorithm versions 6 to 9 were informed by expert opinion, when disseminated for peer review, with the Working Party meeting formally, approximately every 6 months, to consider suggestions from stakeholder representatives. Finally, versions 10 and 11 were developed with similar methodology as versions 1-5, using data collected from consenting candidates at three tracheostomy safety courses. Candidates undertook the same scenarios that were used to develop the initial algorithms and were assessed by members of the original Working Party. The final algorithm was agreed when no further recommendations were made for revisions. A final cycle of peer review and endorsement by stakeholder organisations agreed this final version with no further algorithm changes recommended.

\section{Results}

A total of 11 drafts of a generic emergency algorithm were tested and refined over a 4-year period. These scenarios were undertaken by those from a multidisciplinary background, most with experience in managing tracheostomy patients. 
Examples where feedback from these sessions resulted in revisions include:

1. Structuring key parts into clearly identified sections, allowing primary responders to work faster (from timed evaluation) and more confidently (from feedback) through initial key steps.

2. Colour coding sections of the algorithm. This helped visually group together a sequence of actions. However, there was no significant measured improvement in performance.

3. Re-ordering elements. Candidates moved faster through the algorithm if early steps reflected their usual practice, presented in a clinically logical order.

\section{Discussion}

The role of high-fidelity medical simulation in recreating reported patient safety incidents and analysing key steps, missed opportunities and potential interventions was key in developing our emergency tracheostomy algorithms. Repeating standardised scenarios whilst following subtly different algorithms allowed refinement of guided responses and this approach led to significantly more changes than those returned by expert peer review.

This process also provided other important developments. Debrief discussions led to the use of different colour schemes to distinguish between patients with tracheostomies and laryngectomies, with matching bedhead signs displaying essential information to all responders in an emergency.[2,4] The hi-fidelity simulators offer the ability to 
accurately recreate the same clinical situation, in an appropriate clinical location, permitting different management strategies to be attempted. This allowed us to evaluate primarily the performance of the algorithm, rather than the responder.

For algorithm versions 6-9, we invited feedback from key UK stakeholders with a stated interest in airway management in order to maintain a degree of consistency between the NTSP and other related (resuscitation and airway) algorithms. Minor amendments were subsequently incorporated, although changes during this phase could be considered as stylistic (terminology, colours, box shapes), with no major changes that had not been considered in the simulation testing. It is unknown whether more detailed revisions would have arisen if earlier algorithms were distributed for expert peer review. However, refinement of our early algorithms using simulation resulted in many more changes than the methodologies described in typical emergency algorithm development.

Our methodology may be difficult to reproduce as much of the data collected was subjective, uncontrolled, subject to bias, and included feedback from participants. However, similar projects are likely to also use experienced 'experts' to evaluate performance which may limit ambiguity.

We conclude that medical simulation has an important role in the initial development and refinement of airway management algorithms and this methodology may compliment or challenge the established methodologies for developing similar guidelines. 


\section{Financial disclosures summary}

Drs McGrath, Bates and Atkinson have received sponsorship from CAE Healthcare to attend HPSN Europe and World events in 2012 and 2013. Sponsorship covered travel and subsistence only.

\section{Competing Interests}

The authors declare no competing interests

\section{Contributorship Statement}

The concept of the study was designed by Dr McGrath, Dr Atkinson, Dr Moore and Dr Bates. Data collection was also performed by Dr McGrath, Dr Atkinson, Dr Moore and Dr Bates. Literature review and data analysis was led by Dr McGrath, updated by Dr Donaldson and Dr Hughes. Manuscript writing had contributions from all, led by Dr McGrath, Dr Donaldson and Dr Hughes. This final revision was signed off by all co-authors. 


\section{References}

1 Lucisano KE, Talbot LA. Simulation training for advanced airway management for anesthesia and other healthcare providers: a systematic review. AANA J 2012;80:25-31.

2 McGrath BA, Bates L, Atkinson D, et al. Multidisciplinary guidelines for the management of tracheostomy and laryngectomy airway emergencies. Anaesthesia 2012;67(9):1025-41.

3. Thomas AN, McGrath BA. Patient safety incidents associated with airway devices in critical care: a review of reports to the UK National Patient Safety Agency. Anaesthesia 2009;64(4):358-65.

4. Brook I. A physician's personal experience as a neck breather needing emergency care. American Journal of Emergency Medicine 2011;29:2334. 